\title{
Burden of Disease Due to Outdoor Air Pollution in Korea: Based on $\mathbf{P M}_{10}$
}

\author{
Hyun-Jin Kim, Seok-Jun Yoon*广, Hyeongsu Kim**, Kun-Sei Lee**, Eun-Jung Kim***, \\ Min-Woo Jo****, and In-Hwan $\mathrm{Oh}^{*}$ \\ Department of Occupational Therapy, Woosong University, Korea \\ Department of Preventive Medicine, College of Medicine, Korea University, Korea* \\ Department of Preventive Medicine, School of Medicine, Konkuk University, Korea** \\ Department of Nursing, Cheju Halla College, Korea*** \\ Department of Preventive Medicine, College of Medicine, University of Ulsan, Korea****
}

\begin{abstract}
Purpose: This study measured the burden of disease in Korea related to outdoor air pollution using disabilityadjusted life year (DALY).

Materials and Methods: As a risk factor of outdoor air pollution, particulate matter with a diameter less than $10 \mu \mathrm{m}\left(\mathrm{PM}_{10}\right)$ was used. First, $\mathrm{PM}_{10}$-related diseases and their relative risk (RR) were selected by means of a literature review. Second, population attributable fractions were computed by using formulae including RR and population exposure to $\mathrm{PM}_{10}$. Third, DALYs of $\mathrm{PM}_{10}$-related diseases in Korea were estimated. Finally, the attributable burden of disease due to $\mathrm{PM}_{10}$ was measured as the sum of the products that multiplied the DALYs of $\mathrm{PM}_{10}$-related diseases by their population attributable fractions.
\end{abstract}

Results: The disease burden of $\mathrm{PM}_{10}$ was 6.9 DALY per 1,000 persons in 2007. The attributable burden of $\mathrm{PM}_{10}$ was 2.68 for lung cancer, 2.41 for COPD, 0.62 for ischemic heart disease, 0.61 for pneumonia, 0.55 for asthma, and 0.03 for preterm.

Conclusions: This study showed the environmental burden of disease of $\mathrm{PM}_{10}$ and burden of $\mathrm{PM}_{10}$-related disease through objective data. It also suggested that active efforts are needed to continuously measure and reduce the burden of environmental diseases in Korea.

Key words: Outdoor air pollution, $\mathrm{PM}_{10}$, Disability adjusted life year (DALY), Burden of disease

\section{Introduction}

In 2006, WHO suggested modifiable environments with eight categories which could be prevented among risk factors that cause environmental disease and measured environmental burden of disease (EBD) with disability-adjusted life year (DALY). Korea ranked $51^{\text {th }}$ (192 countries) with 23 DALY per 1,000 cap. and more precisely, the estimates of burden of outdoor air pollution using $\mathrm{PM}_{10}$ was 0.9 DALY per 1,000 cap. in 2006. However the WHO study has limitation that DALY is estimated by applying the $\mathrm{PM}_{10}$ levels of the urban areas with populations greater than 100,000 and using common exposure rates by dividing into six regions, not by specific countries. In addition, the WHO study used several collected information on which sources were inaccurate or not suitable in measuring the incidence and the mortality rate., ${ }^{1,2}$

Therefore, this study was intended to measure the burden of disease of outdoor air pollution (especially $\mathrm{PM}_{10}$ ) using DALY in Korea, by means of the

\footnotetext{
Corresponding author: Department of Preventive Medicine, College of Medicine, Korea University, Seoul 136705, Korea, Tel.:+82-2-920-6412, Fax.:+82-2-927-7220, E-Mail: yoonsj02@korea.ac.kr Received: 17 October 2011, Revised: 24 October 2011, Accepted: 26 October 2011
} 
method that the WHO and GBD (Global Burden of Disease) group suggested.

\section{Materials and Methods}

\section{Study data}

To measure the burden of disease of particulate matter, exposure data of $\mathrm{PM}_{10}$, relative risks necessary to present correlation between $\mathrm{PM}_{10}$ and each disease, and data to calculate DALY of $\mathrm{PM}_{10^{-}}$ related diseases were used.

\section{Exposure data of $\mathbf{P M}_{10}$}

In this study, among 5 air pollutants whose emission amounts were obtained from the National Institute of Environmental Research (NIER) of the Ministry of Environment, $\mathrm{PM}_{10}$ was used as exposure index, which is frequently used for air pollution epidemiology studies and has significant effects on human body.

For the $\mathrm{PM}_{10}$ data, the measured values of 394 monitoring stations in 83 'city' and 'county' around the nation were applied according to the trend transition table of the air pollution levels which is presented in the Annual Report of Ambient Air Quality in Korea (2007), published by the NIER every year. ${ }^{3)}$

\section{Data for choosing relative risk of $\mathbf{P M}_{10}$-related} diseases

To select $\mathrm{PM}_{10}$-related diseases and to express the relationship between $\mathrm{PM}_{10}$ and each disease, the relative risk, which is necessary to calculate the attributable risk, was chosen through literature review.

\section{Data for measuring the burden of the $\mathrm{PM}_{10^{-}}$ related diseases}

To consider the burden of $\mathrm{PM}_{10}$-related diseases, the statistics of the cause of death obtained from the Korea National Statistical Office (KNSO) and life table of KNSO were investigated. ${ }^{4)}$ In addition, to obtain incidence rate, data on health care utilization for diseases related to $\mathrm{PM}_{10}$ from Health Insurance Review Agency (HIRA) for 2004 2007 was used.

\section{Methods}

\section{1. $P M_{10}$-related diseases and relative risks}

To review articles, an electronic data base (DB) search was conducted by dividing criteria into foreign and domestic, where PUBMED and National Assembly Library of Korea, KoreaMed and Kmbase were used for foreign and domestic articles respectively. The papers searched were published from January 1, 1990 to November, 2008. For disease selection, the categories of diseases due to outdoor air pollution presented in EBD studies were utilized. $\mathrm{PM}_{10}$-related diseases and relative risks are divided into categories such as respiratory diseases, perinatal conditions, congenital abnormalities, neoplasm, cardiovascular diseases, COPD and asthma in EBD studies. ${ }^{5)}$ When domestic articles were searched, major search words included "outdoor air pollution" and " $\mathrm{PM}_{10}$ ". Secondarily, a manual search was performed using references from DB searched papers to select further articles for use in this study.

Criteria for selection of literature regarding $\mathrm{PM}_{10^{-}}$ related diseases were as follows. Firstly, an article should highlight diseases caused by $\mathrm{PM}_{10}$ and demonstrate their relative risk. Secondly, our study design included the ecological study, case series study and time series study which present the correlations of change patterns between the specific diseases as well as the cohort study. Thirdly, when various studies were found according to diseases, a cohort study was selected first. In the case where there was no cohort study on a disease, an ecological study and time series study were chosen. In addition, among studies with same study design, studies recruiting Koreans or Asians as subjects were selected. After selecting only diseases with a 
Table 1. $\mathrm{PM}_{10}$-related diseases and its relative risks

\begin{tabular}{|c|c|c|c|c|}
\hline Disease & & Exposure level & "Relative risks & 95\% Confidence Interval \\
\hline \multirow[t]{2}{*}{ Lung cancer ${ }^{\text {) }}$} & male & $51.24 \mu \mathrm{g} / \mathrm{m}^{3}$ & 3.36 & $(1.57-7.19)$ \\
\hline & female & $51.24 \mu \mathrm{g} / \mathrm{m}^{3}$ & 1.33 & $(0.60-2.96)$ \\
\hline Coronary heart disease $^{7)}$ & & $21.00 \mu \mathrm{g} / \mathrm{m}^{3}$ & 1.43 & $(1.10-1.86)$ \\
\hline Low birth weight ${ }^{8)}$ & & $50.00 \mu \mathrm{g} / \mathrm{m}^{3}$ & 1.33 & $(1.02-1.74)$ \\
\hline Preterm $^{9)}$ & & $64.56 \mu \mathrm{g} / \mathrm{m}^{3}$ & 1.27 & $(1.04-1.56)$ \\
\hline Pneumonia $^{10)}$ & & $45.00 \mu \mathrm{g} / \mathrm{m}^{3}$ & 1.19 & $(1.07-1.32)$ \\
\hline Sudden infant death syndrome ${ }^{11)}$ & & $28.40 \mu \mathrm{g} / \mathrm{m}^{3}$ & 1.12 & $(1.07-1.17)$ \\
\hline Asthma ${ }^{12)}$ & & $60.00 \mu \mathrm{g} / \mathrm{m}^{3}$ & 1.11 & $(1.03-1.19)$ \\
\hline Still birth ${ }^{13)}$ & & $89.10 \mu \mathrm{g} / \mathrm{m}^{3}$ & 1.09 & $(1.04-1.15)$ \\
\hline Chronic bronchitis $^{14)}$ & & $50.00 \mu \mathrm{g} / \mathrm{m}^{3}$ & 1.05 & $(1.015-1.077)$ \\
\hline $\operatorname{COPD}^{15)}$ & & $51.53 \mu \mathrm{g} / \mathrm{m}^{3}$ & 1.02 & $(1.006-1.041)$ \\
\hline Ischemic heart disease $^{15)}$ & & $51.53 \mu \mathrm{g} / \mathrm{m}^{3}$ & 1.01 & $(1.001-1.025)$ \\
\hline
\end{tabular}

causal relation through literature review, 35 papers were selected finally. The $\mathrm{PM}_{10}$-related diseases were categorized into neoplasm, infant related diseases, respiratory diseases and cardiovascular diseases. As only a paper on lung cancer was shown by separating into males and females, relative risk of lung cancer is presented by dividing gender. Also, the relative risk of lung cancer for female showed no statistically significant (RR 1.33, 95\% CI 0.60 2.96). However, we adopted this RR to calculate the burden of disease due to the inadequacy of data (Table 1).

\section{Calculating population exposure due to $\mathbf{P M}_{10}$} and attributable risk

To calculate population exposure (Pe) of a population, the resident registered population (2007) from KNSO according to 'city' and 'county' were used and measured values of 394 stations in 83 city and county around the nation were applied. The exposure level of air pollution was an annual average based on the data from the Air Quality Research Division of NIER, and when two or more measurement points for automatic air quality monitoring were located in city or county, their average was used. In the case where there was no point for automatic air quality monitoring in city or county, $\mathrm{PM}_{10}$ level was assumed to be less than the
Table 2. Exposure difference and attributable fraction

\begin{tabular}{ccc}
\hline \hline Disease & $\begin{array}{c}\text { Exposure } \\
\text { difference } \\
\left(\text { Unit: } \mu \mathrm{g} / \mathrm{m}^{3}\right)\end{array}$ & $\begin{array}{c}\text { Attributable } \\
\text { fraction } \\
(\%)\end{array}$ \\
\hline Lung cancer & 50 & 29.1 \\
& $51-75$ & 69.70 \\
& $76-100$ & 1.15 \\
\hline Ischemic heart & 50 & 29.1 \\
disease & $51-60$ & 32.76 \\
& $61-70$ & 35.1 \\
& $71-80$ & 2.99 \\
\hline COPD & 51 & 32.2 \\
& $52-61$ & 34.43 \\
& $62-71$ & 30.34 \\
& $72-81$ & 2.99 \\
\hline Pneumonia & 45 & 18.55 \\
& $46-145$ & 81.45 \\
\hline Asthma & 60 & 61.89 \\
& $61-92.6$ & 38.11 \\
\hline Preterm & 64.56 & 83.01 \\
& $64.57-106.39$ & 16.98 \\
\hline
\end{tabular}

average annual criterion of Korea $\left(50 \mu \mathrm{g} / \mathrm{m}^{3}\right)$.

Out of the total population of Korea $(49,268,928$ persons) in 2007, 7,942,731 lived in city and county without the point for automatic air quality monitoring. The comparative risk of residents in exposed areas according to exposure level was calculated based on a multiplicative model as the level of surpassing 
exposure criterion point (Table 2). ${ }^{16)}$

Population Attributable Fractions (PAF) was defined by how much percent of incidence of the disease are caused by exposure to health risk factor. Therefore attributable burden of health risk factor was measured by multiplying DALY of each disease with PAF (Table 3).

\section{Measuring DALY of $\mathrm{PM}_{10}$-related diseases}

DALY was calculated by adding years of Life Lost (YLL) due to premature death and years lived with disability (YLD) due to disability.

$$
\mathrm{DALY}=\mathrm{YLL}+\mathrm{YLD}
$$

\section{Measuring YLL due to $\mathrm{PM}_{10}$-related diseases}

Firstly, with the data on death causes from KNSO and life table (KNSO) in 2007, standardized life expectancy according to age, gender and causes of the death were investigated ${ }^{4)}$. Secondly, to calculate the years of life lost due to premature mortality by age group, Standard Expected Years of Life Lost (SEYLL) was used. Thirdly, this study applying the estimated variables to the formula that estimates the years of life lost due to premature mortality, calculated burden of disease due to premature death. $^{17)}$

\section{Measuring the YLD due to $\mathbf{P M}_{10}$-related} diseases

Incidence rate of diseases related to $\mathrm{PM}_{10}$ was

Table 3. Population attributable fractions of $\mathrm{PM}_{10}$-related disease

\begin{tabular}{ccc}
\hline \hline \multicolumn{1}{c}{ Disease } & PAF \\
Lung cancer & male & 0.6837 \\
& female & 0.2057 \\
Ischemic heart & & 0.3265 \\
disease & 0.3024 \\
COPD & 0.1340 \\
Pneumonia & 0.1319 \\
Asthma & 0.0679 \\
Preterm & \\
\hline
\end{tabular}

http://www.kseh.org/ calculated using the insurance claim data from HIRA for 2004 2007. To calculate fatality rate, the number of deaths was investigated using the data on death causes of KNSO in 2007, and the average age at disease onset and the morbidity period except remission rate were calculated using the DISMOD II model. And this study used Korean disability weights to reflect to precise condition of Korean patients $^{18)}$.

\section{Measuring the attributable burden of $\mathrm{PM}_{10^{-}}$ related diseases}

To measure attributable burden of $\mathrm{PM}_{10}$, values multiplying DALY of each disease with PAF, meaning how much percent of occurrences of the disease are caused by exposure to $\mathrm{PM}_{10}$, were added.

Attributable burden $=$ DALY $\times$ PAF

\section{Results}

\section{Attributable burden of $\mathbf{P M}_{10}$}

Comparison of these results according to $\mathrm{PM}_{10^{-}}$ related diseases and gender was presented in Table 4.

The burden of disease attributable to $\mathrm{PM}_{10}$ measured by DALY was 6.9 (unit: DALY per 1,000 persons) in 2007. Attributable burden of lung cancer was the highest, 2.68 (38.9\%), and COPD followed it by $2.41(34.9 \%)$. Ischemic heart disease, pneumonia, asthma and preterm recorded 0.62 (9\%), 0.61 (8.8\%),

Table 4. Attributable burden of diseases by $\mathrm{PM}_{10}$ in Korea (unit: DALY/1,000 cap. in 2007)

\begin{tabular}{cccc}
\hline \hline \multirow{2}{*}{ Disease } & \multicolumn{3}{c}{ Outdoor air pollution } \\
\cline { 2 - 4 } & Total (\%) & Male (\%) & Female (\%) \\
\hline Lung Cancer & $2.68(38.9)$ & $2.42(48.2)$ & $0.26(13.8)$ \\
COPD & $2.41(34.9)$ & $1.51(30.1)$ & $0.90(47.7)$ \\
Ischemic Heart & $0.62(9)$ & $0.38(7.6)$ & $0.24(12.7)$ \\
Disease & & & \\
Pneumonia & $0.61(8.8)$ & $0.36(7.2)$ & $0.25(13.3)$ \\
Asthma & $0.55(8)$ & $0.33(6.6)$ & $0.22(11.7)$ \\
Preterm & $0.03(0.4)$ & $0.013(0.3)$ & $0.015(0.8)$ \\
Total & $6.9(100)$ & $5.01(100)$ & $1.89(100)$ \\
\hline
\end{tabular}


Table 5. Attributable burden of diseases due to outdoor air pollution in men according to age group

(unit: DALY/1,000 cap. in 2007)

\begin{tabular}{ccccccccccc}
\hline \hline & $0-9$ & $10-19$ & $20-29$ & $30-39$ & $40-49$ & $50-59$ & $60-69$ & $70-79$ & $80-89$ & $90+$ \\
\hline Asthma & 0.067 & 0.016 & 0.006 & 0.018 & 0.056 & 0.058 & 0.059 & 0.038 & 0.009 & 0.000 \\
COPD & 0.050 & 0.031 & 0.024 & 0.059 & 0.314 & 0.351 & 0.353 & 0.250 & 0.074 & 0.003 \\
Lung Cancer & 0.000 & 0.003 & 0.008 & 0.045 & 0.220 & 0.523 & 0.880 & 0.623 & 0.111 & 0.002 \\
Pneumonia & 0.062 & 0.01 & 0.009 & 0.045 & 0.071 & 0.054 & 0.050 & 0.042 & 0.017 & 0.001 \\
$\begin{array}{c}\text { Ischemic } \\
\text { Heart Disease }\end{array}$ & 0.000 & 0.001 & 0.005 & 0.026 & 0.084 & 0.119 & 0.095 & 0.042 & 0.006 & 0.000 \\
Preterm & 0.009 & 0.004 & 0.000 & 0.000 & 0.000 & 0.000 & 0.000 & 0.000 & 0.000 & 0.000 \\
\hline
\end{tabular}

Table 6. Attributable burden of diseases due to outdoor air pollution in women according to age group (unit: DALY/1,000 cap. in 2007)

\begin{tabular}{ccccccccccc}
\hline \hline & $0-9$ & $10-19$ & $20-29$ & $30-39$ & $40-49$ & $50-59$ & $60-69$ & $70-79$ & $80-89$ & $90+$ \\
\hline Asthma & 0.056 & 0.009 & 0.007 & 0.015 & 0.015 & 0.012 & 0.032 & 0.052 & 0.019 & 0.001 \\
COPD & 0.047 & 0.015 & 0.044 & 0.075 & 0.071 & 0.093 & 0.242 & 0.210 & 0.088 & 0.007 \\
Lung Cancer & 0.000 & 0.000 & 0.003 & 0.014 & 0.034 & 0.051 & 0.064 & 0.070 & 0.026 & 0.003 \\
Pneumonia & 0.050 & 0.008 & 0.008 & 0.010 & 0.012 & 0.018 & 0.043 & 0.058 & 0.037 & 0.005 \\
$\begin{array}{c}\text { Ischemic } \\
\text { Heart Disease }\end{array}$ & 0.000 & 0.001 & 0.002 & 0.006 & 0.033 & 0.062 & 0.074 & 0.048 & 0.013 & 0.001 \\
Preterm & 0.015 & 0.000 & 0.000 & 0.000 & 0.000 & 0.000 & 0.000 & 0.000 & 0.000 & 0.000 \\
\hline
\end{tabular}

$0.55(8 \%)$ and $0.03(0.4 \%)$, respectively.

In males, $\mathrm{PM}_{10}$-attributable burden of the diseases was lung cancer $(48.2 \%)$, COPD (30.1\%), ischemic heart disease $(7.6 \%)$, pneumonia $(7.2 \%)$ and asthma $(6.6 \%)$ respectively in that order. For women, COPD (47.7\%) showed the largest burden and lung cancer $(13.8 \%)$, pneumonia $(13.3 \%)$, ischemic heart disease $(12.7 \%)$ and asthma (11.7\%) followed it in that order.

\section{Attributable burden according to $\mathrm{PM}_{10}$-related} diseases, gender and age

According to the results of attributable burden based on age, the burden of asthma as well as pneumonia were higher among infants and children aged less than 10 years in both males and females and they tended to decline after the ages. The burden of premature birth among infant-related diseases accounted for a relatively small portion, at $0.4 \%$ of the total burden of diseases caused by $\mathrm{PM}_{10}$. However, it was present only under the age of 10 and the burden value was larger in female infants than in male infants.

Attributable burden of COPD was the largest in the 20s age group and its burden showed high levels at $30 \mathrm{~s}$ and at $40 \mathrm{~s}$ in males and females, respectively. Among the 50s age group in males, the attributable burden of lung cancer was highest and the burden of males skyrocketed after 40s. For females, the burden of COPD, and ischemic heart disease were at high levels among the $50 \mathrm{~s}$ age group. The burden of lung cancer reached its highest level in the 60s men's age group but it reduced over-70 age group. For 60s females' age group, it showed a similar tendency starting at the 50s age group (Table 5, 6).

\section{Discussion}

This study estimated attributable burden of $\mathrm{PM}_{10}$ among the outdoor air pollutants by using measurement indicator DALY, and the total burden 
was 6.9 (unit: DALY/1000 persons) in 2007. Measurement of attributable burden caused by $\mathrm{PM}_{10}$ found that the burden was larger in males than in females overall. For men, lung cancer and COPD were the highest burden of disease. And COPD, ischemic heart disease accounted for largest portion in females.

However, this result can be considered that there are significant differences from Korea's attributable burden (0.9 DALY/1,000 cap.) due to outdoor air pollution measured by WHO in 2006. The main causes for those differences are the fact that the urban areas, targeted to estimate exposure level of outdoor air pollution, were not around nation but those with population over 100,000.

The applied average level of $\mathrm{PM}_{10}$ was $43 \mu \mathrm{g} / \mathrm{m}^{3}$ in 2004. Thus this result was estimated to be less than $50 \mu \mathrm{g} / \mathrm{m}^{3}$, the Korea's average level of $\mathrm{PM}_{10}$ in 2007. In addition, this study used literature review to calculate relative risk of $\mathrm{PM}_{10}$ and domestic epidemiological data such as mortality, incidence, and prevalence rate were used. In the case of EBD study, mortality rate was used by specific countries such as Korea. However data such as prevalence, incidence rate were applied only by 14 subregions, not by specific countries. Therefore EBD results of WHO are thought to be underestimated comparing those of this study.

A study on the burden of disease due to $\mathrm{PM}_{10}$ of the outdoor air pollutants in South Africa calculated only YLL by using $\mathrm{PM}_{10}, \mathrm{PM}_{2.5}$, thus it was not able to directly compare the size of the burden of disease. $^{19)}$ In males, YLL were ischemic heart disease $(5,694)$, stroke $(4,479)$, lung cancer $(2,449)$, COPD $(2,385)$ and in females, YLL was stroke $(6,144)$, ischemic heart disease $(4,088)$, hypertensive disease $(3,239)$, COPD $(1,415)$. Therefore the burden of high mortality rate disease was bigger than high morbidity rate disease, which was slightly different from the result of this study. In addition, considering the other studies on burden of disease of Korean people in 2005 , the burden of disease attributable to smoking was 271.78 for males and 72.67 for females (unit: DALY/1,000 cap). Attributable burden of smoking in males was pneumonia \& influenza (71.974), ischemic heart disease (23.66), trachea/ lung/bronchus cancer (4.809), chronic airways obstruction (3.18) and attributable burden of smoking in females were pneumonia \& influenza (12.657), ischemic heart disease (3.691), chronic airways obstruction (1.246), trachea/lung/bronchus cancer $(0.966){ }^{20)}$ Thus it showed that the burden of disease due to smoking is bigger than the burden of disease due to outdoor air pollution.

From results on attributable burden of $\mathrm{PM}_{10}$ according to gender, lung cancer accounted for the largest portion, $48.2 \%$ of the total burden of air pollution in males. Currently, the most well-known factor for causing lung cancer is smoking ${ }^{20)}$. And according to a study that measured the burden of disease of Koreans in 2002, the burden of trachea, lung, and bronchus cancer due to smoking accounted for 4.81 in males, 0.966 in females (unit: DALY /1,000 cap). ${ }^{20)}$ However exposure to radon and occupational materials such as arsenic and asbestos and air pollution has reported to increase the incidence of lung cancer, except smoking. ${ }^{21,22)}$ Therefore air pollution is associated with increased incidence of lung cancer and policies for improvement of air quality to decrease $\mathrm{PM}_{10}$ are thought to be performed continuously.

In our study what ranked second in attributable burden of $\mathrm{PM}_{10}$ in males was COPD and it accounted for $30.1 \%$ of the total burden. Moreover, it showed the largest level in females by recording $47.7 \%$ of the total burden of females. These results are similar with epidemiological reports on COPD and prevalence and mortality rates of COPD have grown steadily in mainly developed countries. ${ }^{23)}$ High smoking rate in the past and an astonishing increase of aged population are considered to be the main contributing causes. Because COPD tends to be diagnosed in smokers in their $40 \mathrm{~s}$ or $50 \mathrm{~s}$ with a history of smoking, the tendency is same with the 
result of this study that $\mathrm{AB}-\mathrm{PM}_{10}$ was increased at $40 \mathrm{~s}$ in comparison according to age. ${ }^{24)}$

For females, the weight of COPD in the total burden was less than that of males by recording $47.7 \%$ and lung cancer, pneumonia, ischemic heart disease and asthma except COPD showed similar weights with men.

When the burden of disease was compared to age, the burden of asthma and pneumonia was large in infants and children aged less than 10 years in both of males and females, tended to decrease after that time and then increased again. This result is same with epidemiological surveys on air pollution performed by restricting subjects to children ${ }^{25-27)}$ and the higher burden is observed because during the time respiratory organs form, their respiratory rate is higher than adults and they are outside longer to be exposed to air pollution for a long time. ${ }^{28)}$

However, materials and method used in this study had following limitations. First, in using articles showing a causal relation between $\mathrm{PM}_{10}$ and a disease, the studies on cardiovascular and respiratory diseases and neoplasm, except for infant-related diseases, were conducted in foreign countries. Although epidemiological studies on air pollution performed in Korea also investigated respiratory and cardiovascular diseases, death, asthma and allergy, they did not meet inclusion criteria of this study. An epidemiological survey on impact of air pollution on delivery was performed first in Korea in around 2000 and some research reported that air pollution was related with the risk of delivery of underweighted newborn infants. Based on the results the PAF of infant-related diseases was calculated by using domestic data. ${ }^{29)}$ In addition, the studies on cardiovascular and lung diseases used in this study were conducted with Asians as their subjects rather than others who showed different patterns of diseases. For other diseases except them mentioned above, we tried to search studies performed with Asians as subjects but we could not find any one by limiting a risk factor to $\mathrm{PM}_{10}$ although there was some research on correlation between increasing incidence of lung cancer and indoor air pollution (use of fossil fuel), radon and environmental tobacco smoking. More epidemiological studies on air pollution related diseases with Koreans are needed to be conducted in the future.

Second, this study chose papers with larger-scaled study design and domestic papers to determine PAF among several searched articles. However, examining relative risk through systemic review as suggested in GBD methodology or estimating overall or average impact (pooled RR) through meta-analysis for papers presenting relative risks are considered to be more reliable. In addition, as each paper has different exposure criteria in evaluating the attributable risk of a risk factor, a method of measuring it with a standard of air pollution criterion of WHO (annual average of $\left.20 \mu \mathrm{g} / \mathrm{m}^{3}\right)$ or that of Korea $\left(50 \mu \mathrm{g} / \mathrm{m}^{3}\right)$ is necessary.

Lastly, this study examined only $\mathrm{PM}_{10}$ as a risk factor to assess attributable burden due to outdoor air pollution. However it is necessary to consider that also $\mathrm{PM}_{2.5}$ and gaseous materials (NOx, SOx, $\mathrm{CO}, \mathrm{O}_{3}$, etc.) should be evaluated as risk factors of air pollution to calculate more accurate burden of disease.

This study suggested that the environmental burden of disease of $\mathrm{PM}_{10}$ by using domestic data. These estimates showed the range of air pollution problems out of environmental pollution ones and proposed prediction needed politically. Therefore air pollution control should be conducted first compared to other interventions to promote public health and active efforts are needed to measure and reduce the burden of environmental disease continuously in Korea.

\section{Acknowledgements}

The authors would like to thank Sung-Jun Jo, Ho-Jang Kwon, Ho Kim, Hae-Gwan Jung, Ji-Youn Yang and Won-Jin Lee for their participation in the 
Korea E-BOD project. This work was supported by the Korea Ministry of Environment (Grant No. 20080906057-00).

\section{References}

1. Country profiles of environmental burden of disease website. Available at http://www.who.int/ quantifying_ehimpacts/national/countryprofile/ republicofkorea.pdf. November 29, 2008.

2. Ostro B. Outdoor air pollution: Assessing the environmental burden of disease at national and local levels. Geneva, World Health Organization, 2004.

3. Annals of atmospheric environment, Ministry of Environment; 2007; p.270.

4. Report on Death Causes 2007. Korea National Statistical Office. Daejeon: Korean National Statistical Office: 2008. (Korean).

5. Quantification of the disease burden attributable to environmental risk factor, WHO, 2006.

6. Abbey DE, Nishino N, McDonnell WF, Burchette RJ, Knutsen SF, Lawrence BW, et al. Long-term inhalable particles and other air pollutants related to mortality in nonsmokers. Am JRespir. Crit. Care Med. 1999; 159: 373-382.

7. Puett RC, Schwartz J, Hart JE, Yanosky JD, Speizer FE, Suh H, et al. Chronic Particulate Exposure, Mortality, and Coronary Heart Disease in the Nurses' Health Study. Am J Epidemiol. 2008; 168: 1161-1168.

8. Dugandzic R, Dodds L, Stieb D, Smith-Doiron M. The association between low level exposure to ambient air pollution and term low birth weight retrospective cohort study 2006. Environ Health. 2006; 17: 5-3.

9. Leem JH, Kaplan BM, Shim YK, Pohl HR, Gotway CA, Bullard SM, et al. Exposures to air pollutants during pregnancy and preterm delivery. Environ Health Perspect. 2006; 114: 905-10.

10. Schwartz J. Air Pollution and Hospital Admissions for the Elderly in Birmingham, Alabama. Am J Epidemiol. 1994; 139: 589-598.

11. Kaiser R, Romieu I, Medina S, Schwartz J, Krzyzanowski M, Künzli N. Air pollution attributable postneonatal infant mortality in U.S. metropolitan areas: a risk assessment study. Environ Health. 2004; 5: 3-4.

12. Lipsett M, Hurley S, Ostro B. Air Pollution and Emergency Room visits for asthma in Santa Clara County, California. Environmental Health Perspec- tives. $1997 ; 105 ; 216-222$.

13. Kim OJ, Ha EH, Kim BM, Seo JH, Park HS, Jung $\mathrm{WJ}$, et al. $\mathrm{PM}_{10}$ and pregnancy outcomes: a hospital-based cohort study of pregnant women in Seoul. J Occup Environ Med. 2007; 49: 1394-1402.

14. Kan HD, Chen BH, Chen CH, Wang BY, Fu QY. Establishment of Exposure-response functions of air particulate matter and adverse health outcomes in China and Worldwide. Biomed Environ Sci. 2005; 18: $159-63$.

15. Wong $\mathrm{T}$, Tam $\mathrm{W}, \mathrm{Yu} \mathrm{T}$, Wong A. Association between daily mortalities from respiratory and cardiovascular diseases and air pollution in Hong Kong, China. Occup Environ Med. 2002; 59: 30-35.

16. Murray CJL, Lopez AD. The Global Burden of Disease. Geneva, World Health Organization, Harvard School of Public Health, World Bank. 1996.

17. Lee JK, Kim YI, Yoon SJ, Lee JY, Lee HY, Park $\mathrm{JH}$, et al. Estimating the burden of diseases due to high alcohol consumption in Korea. Korean J Prev Med Public Health. 2005; 38:175-181.

18. Lee JK, Yoon SJ, Do YK, Kim CH, Park KD et al., Disability weights for diseases in Korea. Kor J Prev Med. 2003; 36: 1-26 (Korean).

19. Norman R, Cairncross E, Witi J, Bradshaw D. South African comparative risk assessment collaborating group. Estimating the burden of disease attributable to urban outdoor air pollution in South Africa in 2000. S Afr Med J. 2007; 97: 782-790.

20. Yoon SJ. Measuring burden of disease in Korea. Ministry of Health and Welfare, 2005, (p.67, 148, $150,152)$.

21. Alberg AJ, Samet JM. Epidemiology of lung cancer. Chest 2003; 123: 21S-49S.

22. International Agency for Research on Cancer: Tobacco Smoke and Involuntary Smoking. IARC Monograph 83. Lyon: International Agency for Research on Cancer; 2004; p.161.

23. Chan-Yeung M, Ait-Khaled N, White N, Ip MS, Tan WC. The burden and impact of COPD in Asia and Africa. Int JTuberc Lung Dis. 2004; 8: 2-14.

24. Lee K.Y. Epidemiology of COPD. $14^{\text {th }}$ Korean society of Tuberculosis \& respiration Workshop 2001.

25. Norris G, Young Pong SN, Koenig JQ, Larson TV, Sheppard L, Stout JW. An association between fine particles and asthma emergency department visits for children in Seattle. Environ Health Perspect. 1999; 107: 489-493.

26. Lee JT. Association between air pollution and asthma-related hospital admissions in children 
Seoul, Korea: A case-crossover study. Korean $J$ Prev Med. 2003; 36: 47-53.

27. Lee JT, Kim H, Son H, Hong YC, Cho YS, Shin $\mathrm{SY}$, et al. Air pollution and asthma among children in Seoul, Korea. Epidemiology. 2002; 13: 481-484.

28. Dixon JK. Kids need clean air: air pollution and children's health. Fan Community Health. 2002; 24: 9-26.

29. Seo JH, Ha EH, Kim OJ, Kim BM, Park HS, Leem $\mathrm{JH}$, et al. Environmental health surveillance of low birth weight in Seoul using air monitoring and birth data. J Prev Med. 2007; 40: 363-370. 